\title{
Impacts of Offshore Wind Farms On The Atmospheric Environment Over Taiwan Strait During An Extreme Weather Typhoon Event
}

\author{
Tsung-Yu Lee \\ National Taiwan Normal University \\ Yu-Ting Wu \\ National Cheng Kung University \\ Chuan-Yao Lin ( $\sim$ yao435@rcec.sinica.edu.tw ) \\ Academia Sinica \\ Yi-Ying Lin \\ Academia Sinica \\ Yang-Fan Sheng \\ Academia Sinica
}

\section{Research Article}

Keywords: Offshore, Atmospheric Environment, Weather

Posted Date: August 26th, 2021

DOl: https://doi.org/10.21203/rs.3.rs-842008/v1

License: (c) (1) This work is licensed under a Creative Commons Attribution 4.0 International License.

Read Full License

Version of Record: A version of this preprint was published at Scientific Reports on January 17th, 2022.

See the published version at https://doi.org/10.1038/s41598-022-04807-w. 
1 Impacts of Offshore Wind Farms on the Atmospheric Environment over

2 Taiwan Strait During an Extreme Weather Typhoon Event

3

4 Tsung-Yu Lee ${ }^{1}$, Yu-Ting Wu ${ }^{2}$, Chuan-Yao Lin ${ }^{3,}$, Yi-Ying Lin ${ }^{3}$, and Yang-Fan Sheng

5

$6 \quad{ }^{1}$ Department of Geography, National Taiwan Normal University, Taipei, Taiwan.

$7 \quad{ }^{2}$ Department of Engineering Science, National Cheng Kung University, Tainan, Taiwan.

$8 \quad{ }^{3}$ Research Center for Environmental Changes, Academia Sinica, Taipei, Taiwan.

$9 \quad *$ yao435@rcec.sinica.edu.tw

10

11

12

13 Submitted to Scientific Reports: August 24, 2021

14

15 


\section{ABSTRACT}

17 Wind energy is one of the cleanest renewable resources. Through the "Thousand Wind Turbines Project", Taiwan is planning to increase the proportion of power generation from renewable energy and has set a target of $5.7 \mathrm{GW}$ for offshore wind by 2025 . However, the effects of future offshore wind farms (OWFs) over the Taiwan Strait on the atmospheric environment have not been evaluated. This study examined the potential effects of proposed OWFs on the atmospheric environment if the OWFs had existed during Tropical Storm Haitang (July 30-31, 2017) by using the Weather Research and Forecasting (WRF) model. As Tropical Storm Haitang made landfall in southern Taiwan and moved northward, wake effects formed at downstream of the OWFs and weather parameters were affected at the coastal area of western Taiwan. A significant reduction (as high as $6.1 \%$ ) in 24-hour accumulated precipitation was found over the western plain of Taiwan. Concurrently, the divergence increased, corresponding to a reduction in wind speed, vertical velocity, moisture flux, reflectivity and precipitable water-vapor (PWV), whereas a slight warming of near-surface air occurred. Sensitivity simulations demonstrated that the influence of OWF location and wind turbine density should not be ignored. 


\section{Introduction}

33 The global demand for renewable energy is increasing rapidly because the Earth's resources are limited. According to a report published by the International Energy Agency (IEA) [1], renewable energy is expected to increase by approximately $50 \%$, and total installed solar and

wind capacity will overtake both coal and gas to become the largest source of electricity generation globally in the next five years. Wind farms can generate clean electricity by extracting energy from the atmosphere. As wind flow passes through the wind turbine, wakes are generated downwind of the turbine, resulting in the reduction of wind speed, and the disturbed wind flow may affect local weather.

Wind farms considerably affect local circulation and regional weather; if sufficiently large, they may even alter the regional climate. Using a numerical model, Baidya Roy et al. [2] demonstrated that wind farms could substantially alter local meteorological parameters, such as temperature and humidity, as well as surface fluxes. Christiansen and Hasager [3] reported that as wind flow passed through large arrays of wind turbines, the mean wind speed was reduced by 8-9\% and wake length could exceed $20 \mathrm{~km}$.

By conducting modeling studies, researchers have discovered that large-scale wind power may affect the global climate. For example, Keith et al. [4] revealed that large-scale wind power caused a non-negligible climatic change at continental scales by altering surface roughness in two general circulation models. Considering the current and a future scenario, Vautard et al. [5] examined the effect of future potential European wind farms on regional climate by using the 
Weather Research and Forecasting (WRF) model. They found modest changes, generally limited to the winter season, and the impacts remain much weaker than the natural variability. Wang and Prinn [6] suggested that large-scale wind farms can increase global precipitation by $10 \%$ in some areas; however, the overall changes were not significant. Furthermore, Siedersleben et al. [7] indicated that large offshore wind farms (OWFs) could affect local weather and regional microclimate, and thus, might alter regional climate.

\section{Recently, Pan et al. [8] reported that hypothetical OWFs protected the coast from heavy} precipitation during Hurricane Harvey. The horizontal divergence induced by the wind turbines, causing a reduction in vertical motion and precipitation downstream of the farms. Al Fahel and Archer [9] showed that the velocity deficit in wakes affected onshore precipitation and generated a divergence zone, which enhanced the vertical downward motion and suppressed precipitation. In addition, they reported that the effect of onshore precipitation was associated with the distance between OWFs and the coast.

Taiwan is located in the western North Pacific (Fig. 1a), which is one of the most active areas for tropical cyclones. On average, Taiwan experienced 4.8 typhoons per year between 1979 and 2016 [10]. According to Taiwan's "Four-year Wind Power Promotion Plan," a goal of 5.7 GW before 2025 has been set for the capacity of OWFs (https://www.twtpo.org.tw/eng/offshore/directions.aspx). The number of wind turbines is expected to increase rapidly within the next few years. Once a tropical cyclone comes, its circulation could be altered by the OWFs and the coastal area would be influenced. To date, few studies have examined the effect of OWFs on local meteorological parameters and circulation 
over Taiwan, particularly extreme weather events. The objective of this paper is to assess the potential impacts of Taiwan's proposed OWFs during a tropical cyclone by using the WRF model, which could be provided as reference for the authorities in environmental impacts and management. Section 2 describes the model configuration and the proposed OWFs. Section 3 presents a detailed analysis of the potential effects of OWFs and the results of sensitivity simulation. Section 4 summarizes the results.

\section{Model setup and data}

\section{Model configuration}

In this study, the WRF model, version 3.9 [11], was utilized to investigate the effects of proposed OWFs on meteorological parameters over western Taiwan if the OWFs had existed during Tropical Storm Haitang (July 30-31, 2017). Simulations were performed using three nested domains with horizontal grid spacing $6 \mathrm{~km}$ (domain 1, $211 \times 211$ grid points), $2 \mathrm{~km}$ (domain 2 , $211 \times 253$ grid points) and $0.6667 \mathrm{~km}$ (domain 3, $211 \times 313$ grid points), respectively (Fig. 1a). One-way nesting was employed in the simulation. The initial and boundary conditions were provided by the National Centers for Environmental Prediction/National Center for Atmospheric Research (NCEP/NCAR) and Global Data Assimilation System with a resolution of $0.25^{\circ}$ at an interval of 6 hours. The vertical layer consisted of 64 layers with 26 levels below $1 \mathrm{~km}$ and 4 levels within the rotor area (i.e., 28-192 m), which had the lowest eta level of 0.996 (approximately $17 \mathrm{~m}$ above surface) and the highest terrain-following hydrostatic pressure of 10 hPa. The MODIS land use/land cover (LULC) and USGS Global Multi-resolution Terrain Elevation Data (GMTED2010, 30 arc seconds, 1 km) were applied for the WRF model. The 
model was used to simulate 4 days - from 00:00 UTC on July 28, 2017, to 00:00 UTC on August 1, 2017-to examine the effect of proposed OWFs during Tropical Storm Haitang. The first two days were considered the spin-up time of the model, and the model output was hourly. In terms of physical parameterizations, the WRF single-moment 5-class microphysics scheme [12] and land surface physics with the Noah Land Surface Model [13] were adopted in the simulation. Furthermore, the Mellor-Yamada-Nakanishi-Niino 2.5-level planetary boundary-layer scheme [14] was used for wind farm parameterization (WFP) in the WRF model. Fitch et al. [15] developed WFP in the WRF model such that it represents a wind farm as an elevated momentum sink and an added turbulent kinetic energy (TKE) source. On the basis of the method reported by Blahak et al. [16], Fitch et al. [15] modeled the turbine drag by using the total fraction of kinetic energy extracted from the atmosphere by wind turbines, depending on thrust and power coefficients; additional details are given by Fitch et al. [15]. To improve the simulations of the track and intensity, the four-dimensional data assimilation (grid nudging) technique was only used in the outer domain (i.e. domain 1). To examine the effects of proposed OWFs on the atmospheric environment during the study period, differences from the inner domains (i.e. domain 2 and domain 3) between the simulations with OWFs (denoted as "case 711-WTs") and without OWFs (denoted as "case CTRL") were presented in this study.

\section{Proposed OWFs}

In Taiwan, the "Thousand Wind Turbines Project" was approved by the government in 2012. The Bureau of Energy, Ministry of Economic Affairs (MOEA), has been actively promoting wind power development. According to the "Four-Year Wind Power Promotion Plan," the MOEA is planning to increase the proportion of power generated from renewable energy and has 
122

123

124

125

126

127

128

129

130

131

132

133

134

135

136

137

138

139

140

141

142

143

set a target of $5.7 \mathrm{GW}$ for offshore wind by 2025. Most of the proposed OWFs (Fig. 1a) are located offshore of Changhua County, and they have a potential output capacity of $2400 \mathrm{MW}$, accounting for $62.6 \%$ of the total offshore wind power capacity. Moreover, many offshore wind turbines will be installed in the Taiwan Strait within the next few years.

In terms of the power capacity, if we assume that the type of wind turbine is the Vestas V1648.0 MW [17] in this study, then the total number of wind turbines required would be as high as 711. Therefore, we artificially installed 711 wind turbines in this area only in the inner domains (i.e. domain 2 and domain 3) of WRF model, following the offshore wind projects of Taiwan's government. The location of offshore wind farms in the model is shown in Fig. 1a, and at a distance of 40-70 $\mathrm{km}$ from the coastline of Taiwan. The turbine, with a 164-m rotor diameter (D), had a rated capacity of $8.0 \mathrm{MW}$ and a hub height of $110 \mathrm{~m}$ above mean sea level. The cut-in and cut-out wind speeds were 4.0 and $25.0 \mathrm{~m} \mathrm{~s}^{-1}$, respectively. The inter-turbine spacing was $4 \mathrm{D}$ in the east-west direction and 6.4-11.6 D in the south-north direction.

For the sensitivity analysis, three additional simulations with different inter-turbine spacing and OWF locations were examined. Case 178-WTs covered the same area but with double the spacing of wind turbines as in case 711-WTs; thus case 178-WTs had one-fourth the number of wind turbines as case 711-WTs. Case 711-WTs_W was a case in which the OWFs in case 711WTs were moved $20 \mathrm{~km}$ westward. Similarly, case 711-WTs_E was a case in which the OWFs in case 711-WTs were moved $20 \mathrm{~km}$ eastward. 


\section{Results}

145

146

147

148

149

150

151

152

153

154

155

156

157

158

159

160

161

162

163

164

165

\section{Model validation}

To validate the performance of the WRF model, we examined the simulated track and MSLP of Tropical Storm Haitang, and precipitation during the study period against observations. The cyclone best track data and central minimum sea level pressure (MSLP) were obtained from the Japan Meteorological Agency (JMA) typhoon archive (http://www.jma.go.jp/jma/jma-eng/jmacenter/rsmc-hp-pub-eg/besttrack.html). The hourly precipitation was provided by Central Weather Bureau (CWB), Taiwan from 522 rain gauge stations. Fig. 1a and b show the comparison of track and MSLP, respectively, during July 30-31, 2017. Our simulated track was comparable to the observed track, whereas the intensity was underestimated before 03:00 UTC on July 31 (Fig. 1b). In particular, the simulated track agreed favorably with the observed track during the invasion period over Taiwan. The bias of the average track error was estimated to be lower than $22 \mathrm{~km}$ during 06:00-18:00 UTC on July 30, 2017. The simulated central MSLP (Fig. 1b) was slightly underestimated but generally followed the observed trend. The bias was generally lower than $4 \mathrm{hPa}$ after landfall of the tropical storm in western Taiwan. The observed accumulated (06:00-18:00 UTC, 30 July) precipitation was 30-200 mm in southwest Taiwan and could be more than $300 \mathrm{~mm}$ over mountain ranges in southern Taiwan (Fig. 1c). The simulation reasonably reproduced and captured the spatial distribution of accumulated precipitation over Taiwan (Fig. 1c). A strong spatial correlation, with a correlation coefficient as high as 0.73 , was observed between the simulated and observed data. 
Although our simulation focused on the Tropical Strom Haitang, there was another typhoon Nesat coming from the ocean to the northeast of Taiwan on 29 July. In other words, Typhoon Nest was prior to Typhoon Haitang approaching Taiwan (Fig. 2) and the circulations were complex over Taiwan as it was hit by two tropical cyclones during 29-31 July (Fig. 2). Actually, a Fujiwhara effect was observed, i.e. these two tropical cyclones were in the proximity of one another, rotating cyclonically around a common center, and their tracks eventually interfered with each other. Typhoon Nesat made landfall on the northeastern coast of Taiwan at 11:00 UTC on July 29, 2017 (Fig. 2). Concurrently, Tropical Storm Haitang was located in the South China Sea and gradually moved toward southwestern Taiwan. As Typhoon Nesat made landfall over China (at 00:00 UTC 30 July in Fig. 2), its intensity was dramatically weakened. On the other hand, it induced a southwesterly flow over the Taiwan Strait (00:00-03:00 UTC 30 July in Fig. 3). A coupled low-pressure and a counter-clockwise rotation area can be seen around Taiwan, resulting from the interactions of these two cyclonic systems (Fig. 2, Fig. 3). In general, whether the OWFs impacted on atmospheric parameters over western Taiwan or not was strongly related to the location of the typhoon and its induced ambient wind direction. In particular, the mean height of the Central Mountain Range (CMR) in Taiwan (Fig. 1a) is more than $2000 \mathrm{~m}$ [18]. The mountains do not only block but also uplift rainfall systems depending on the location of the cyclone and the direction of rain bands' movement. Therefore, the strength of the effect depended on the variation of the cyclone track and interaction of the wind field with the complex geographic structure. According to the track of Typhoon Nest on 29 July, the wind speed was weak over western Taiwan due to the blocking effect of the CMR (Fig. 2). Thus, in this study, we focused on the passage of Tropical Storm Haitang over Taiwan during 30-31 July 2017. 
To examine the effects of proposed OWFs on the atmospheric environment during an extreme weather event, we conducted simulations with and without the inclusion of OWFs. Data showed that landfall of Tropical Storm Haitang occurred in Pingtung County in southern Taiwan at 08:40 UTC on July 30, 2017. Tropical Storm Haitang moved northward after 09:00 UTC and its lowpressure center was in western Taiwan. However, strong typhoon's cyclonic circulations interacted with the CMR mainly in the eastern of the island and resulted in a weak-wind region (less than $10 \mathrm{~m} \mathrm{~s}^{-1}$ ) on the lee side of the mountains over western Taiwan. It was noted that two different directions' flow, northeasterly and northwesterly interacted at the upstream of OWFs between 09:00-12:00 UTC, on July 30 (Fig. 3). The flow over the Taiwan Strait was replaced with southwesterly between 15:00 and 21:00 UTC (Fig. 3) as Tropical Storm Haitang already moved to the north of OWFs. The wake effects [3,19-21] occurred due to a reduction of wind speed at downwind of OWFs during 09:00-13:00 UTC, on July 30 (Supplementary Fig. S1). Siedersleben et al. [7] used aircraft measurements and the WRF model to investigate all existing and planned wind farms in the North Sea. They reported that the effects of wakes on temperature and water vapor could propagate more than $100 \mathrm{~km}$ downwind under strong stable atmospheric conditions. In Taiwan, the distances of proposed OWFs from the west coast are $40-70 \mathrm{~km}$. Thus, the atmospheric environment over western Taiwan is expected to be strongly affected by wind turbine wakes. Owing to the variation of wind field near the OWFs, the differences between the simulations with and without wind farms in other meteorological parameters (such as hub-height wind speed, hub-height divergence, hub-height vertical velocity and the precipitable watervapor) over western Taiwan were examined from 9:00 UTC to 16:00 UTC 30 July. 
211 Fig. 4 shows the area-mean of the time series of differences in hub-height wind speed, PWV and 212 precipitation over the downwind regions (region I marked by a red box while region II was blue 213 in Fig. 5a) of the OWFs and the west coast of Taiwan (indicated by the grey slashed area in Fig. 214 5a). The mean wind direction presented the variations of the ambient flow at the downwind of 215 OWFs. It was noted that the period of the wind speed reductions in different regions was 216 different according to the ambient wind direction. The wind direction was changing from 217 westerly to northwesterly and so as the wind speed significantly decreased at the downwind of 218 OWFs between 06:00-10:00 UTC in region I (Fig. 4a). A similar wind direction changed also 219 occurred in region II, and so as the wind speed decreased during 10:00-17:00 UTC (Fig. 4b). It could be recognized the propagation of the wake effect from region I and region II as a result of 221 the movement of Tropical Storm Haitang its circulation interacted with OWFs (Fig. 3 and Fig. 4a,b). In general, the wind speed was weak over western Taiwan. Over the west coastal Taiwan, the PWV and precipitation were consistently reduced after 13:00 UTC (Fig. 4c).

Fig. 5a shows a significant reduction in the 24-hour accumulated precipitation between case 711WTs and CTRL over Taiwan. To quantify the reduction in precipitation downwind of OWFs in the western plain, we particularly focused on the area ranging from $23.0^{\circ} \mathrm{N}$ to $24.5^{\circ} \mathrm{N}$ and considered an elevation of fewer than $30 \mathrm{~m}$ in this study (the gray diagonally lined area in Fig. 5a). Simulation results indicated that the average reduction in 24-hour accumulated precipitation over the western plain was approximately $6.1 \%(7.6 \mathrm{~mm})$, with the maximum reduction being up to $47 \%$. However, the precipitation was increase in the Taiwan Strait between the OWFs and the coastline, with a maximum value of approximately $35 \%$, which was associated with the enhanced wind speed (region I in Fig. 4a) owing to the channel effect [22]. The reason for 
234 precipitation decreased onshore while increased offshore was similar to the finding proposed by

235 Pan et al. [8]. Beyond our focus area over a mountain and southern Taiwan, their precipitation

236 differences had nearly dipole patterns. It might be associated with simulation location differences

237 in the cyclone's rain bands between 711-WTs and CTRL cases.

239 Fig. 5b-j presents a time-latitude diagram of the differences between 711-WTs and CTRL

240 simulation, averaging from E-W direction over the western plain marked by grey slashed area in

241 Fig. 5a. The simulation results indicated that the differences in hub-height divergence, wind

242 speed, vertical wind speed, TKE, and moisture flux firstly varied southward and then northward

243 from 06:00 UTC to 18:00 UTC. The reduction of hub-height reflectivity, precipitable water-

244 vapor (PWV), and precipitation can be clearly seen after Tropical Storm Haitang made landfall

245 (at 9:00 UTC 30 July). Precipitation was found to significantly decrease and then propagate

246 northward after Haitang making landfall (Fig. 5i). A maximum reduction of $21 \mathrm{~mm} \mathrm{~h}^{-1}$

247 corresponded to an increase of $1 \times 10^{-3} \mathrm{~s}^{-1}$ in hub-height divergence (Fig. 5b), and a reduction of

$248 \quad 2.6 \mathrm{~m} \mathrm{~s}^{-1}, 5.5 \times 10^{-2} \mathrm{~m} \mathrm{~s}^{-1}, 46 \mathrm{~g} \mathrm{~kg}^{-1} \cdot \mathrm{m} \mathrm{s}^{-1}, 35 \mathrm{dBZ}$ and $3.1 \mathrm{~kg} \mathrm{~m}^{-2}$ in hub-height wind speed (Fig.

249 5c), hub-height vertical velocity (Fig. 5d), hub-height moisture flux (Fig. 5f), hub-height

250 reflectivity (Fig. 5g), and PWV (Fig. 5h), respectively. By contrast, the surface air temperature

251 increased by up to $0.4{ }^{\circ} \mathrm{C}$ (Fig. 5j), which was likely caused by decreased precipitation resulting

252 from the velocity deficit of wind turbine wakes. Overall, over the western plain, wind divergence

253 occurred accompanied by a significant downward motion, less moisture transport, reflectivity,

254 and precipitable water-vapor (PWV), as well as warmer air temperature, which adversely

255 affected precipitation because of the presence of the wind farm. These factors are consistent with

256 those reported by Al Fahel and Archer [9]. 
To further examine the interactions among the complex circulations and OWFs, vertical crosssections along line AB (Fig. 6a) through the OWFs to the shore for WRF model domain 3 (resolution is $0.6667 \mathrm{~km}$ ) at 11:00 UTC, 30 July as shown in Fig. 6. The results shown in Fig. 6 represented the differences between the simulations with and without OWFs. As Tropical Storm Haitang made landfall in southern Taiwan and toward to the north, its cyclonic flow was weakened due to blocking effect of the CMR. It was identified that the horizontal wind speed was over $20 \mathrm{~m} \mathrm{~s}^{-1}$ to the east of the CMR, however, at the lee side of the mountain, the wind speed was less than $10 \mathrm{~m} \mathrm{~s}^{-1}$ around the OWFs and the western plain of Taiwan (Fig. 3).

Fig. 6b-e illustrates the vertical cross-section in NW-ES direction across the OWFs from A to B. Owing to the presence of the OWFs, a maximum wind speed decrease $\left(\sim 3.9 \mathrm{~m} \mathrm{~s}^{-1}, 43.3 \%\right)$ was at the elevation of hub-height $(110 \mathrm{~m})$ within the rear side of the farm (near $\left.119.85^{\circ} \mathrm{E}\right)$. The OWFs not only can block wind speed but also enhance the upward and downward motion above

(Fig. 6b), with a significantly decreased being around. The northwesterly winds were significantly affected over the OWFs as well as the onshore area (Fig. 6b). It can be seen that the divergence zones associated with horizontal wind speed deficit (Fig. 6b), and substantial downward motion (Fig. 6c) from the surface to an elevation of 1000 m. Furthermore, the adverse moisture flux transport (Fig. 6d) resulted in precipitation inhibiting onshore due to downward motion also can be seen in Fig. 5a. The surface air temperature (Fig. 6e) was then further influenced by the OWFs. It was estimated that a horizontal velocity deficit of $6.1 \mathrm{~m} \mathrm{~s}^{-1}(\sim 50 \%$, near the triangle symbol in Fig. 6b), the vertical velocity decreased up to $1.8 \mathrm{~m} \mathrm{~s}^{-1}$ at a height of 
$1000 \mathrm{~m}$ (Fig. 6c) and surface moisture flux also decreased by $125 \mathrm{~g} \mathrm{~kg}^{-1} \cdot \mathrm{m} \mathrm{s}^{-1}(\sim 80 \%)$ over the west coastal area (near the triangle symbol in Fig. 6d). Moreover, air temperature increased by a maximum of $1.6^{\circ} \mathrm{C}(\sim 7.3 \%$, Fig. $6 \mathrm{e})$ at a height of $1000 \mathrm{~m}$ and extend to the surface. This warming was associated with a descending motion and a decreased moisture flux. The higher temperature was due to the enhancement of vertical mixing as well as the contribution of warmer air from above resulting from turbulent mixing. Overall, over the western plain, wind divergence occurred accompanied by a significant downward motion, less moisture transport, and warmer air temperature, which adversely affected precipitation because of the presence of the wind farm.

\section{Sensitivity to OWF location}

Three additional simulations were performed to investigate the sensitivity of the results to OWF location and inter-turbine spacing. The OWF layout for the sensitivity simulations is shown in Fig. 7 and Table 1. We focused on different OWF arrangements and their effects on accumulated precipitation on July 30, 2017. The sensitivity study design considered the number of wind turbines (178-WTs, i.e., one-fourth of the wind turbines as in case 711-WTs; Fig. 7a) and locations of wind farms (Fig. 7b,c).

Fig. 7 and Table 1 show the differences in 24-hour accumulated precipitation between the cases considered in the sensitivity simulations and CTRL. Compared with case 711-WTs (Fig. 5a), a minor decrease in precipitation $(-6.9 \mathrm{~mm},-5.9 \%)$ was found in case $178-$ WTs (Fig. 7a and Table 1). The magnitude of average change in precipitation for case 178 -WTs was smaller than in case $711-W T s(-7.6 \mathrm{~mm},-6.1 \%)$, which was due to the less density of wind turbines. When 
302 the OWF was moved away from the coastline (case 711-WTs_W, Fig. 7b and Table 1), the

303 average difference in simulated precipitation reduction $(-1.8 \mathrm{~mm},-2.1 \%)$ was much smaller

304 than that in case 711-WTs. Furthermore, when the OWF has moved closer to the shore (case

305 711-WTs_E, Fig. 7c), a larger influence on precipitation $(-8.7 \mathrm{~mm},-7.3 \%)$ can be seen over

306 western Taiwan.

307

308 Fig. 8 illustrates the simulated divergence and the difference in precipitation between the

309 sensitivity and CTRL simulations (between $23.0^{\circ} \mathrm{N}$ and $24.5^{\circ} \mathrm{N}$ and between $120.0^{\circ} \mathrm{E}$ and

$310 \quad 120.7^{\circ} \mathrm{E}$, bounded by the grey diagonally lined area in Fig. 5a), and the evolution spanning this

311 area from the south to the north is displayed for the period 00:00 UTC to 23:00 UTC on July 30,

312 2017. The reduction in precipitation was associated with an increase in divergence and is

313 consistent with the findings reported by Pan et al. [8] and Al Fahel and Archer [9]. Moreover, the

314 reduction in precipitation was strongly related to the occurrence of the divergence. The

315 divergence was estimated to increase approximately 1-2 hours earlier than the reduction in

316 precipitation (Fig. 8). When the number of turbines was decreased (by increasing the distance

317 between turbines; case 178-WTs), the reduced precipitation and increased divergence decreased

318 (Fig. 8b). Furthermore, simulation differences between cases 711-WTs_W and 711-WTs_E

319 indicated that OWF location affected the location of divergence similar to precipitation, as

320 shown in Fig. 8c,d.

$322 \mathrm{Al}$ Fahel and Archer [9] suggested that the divergence zone forms and precipitation effects are

323 observed approximately $10 \mathrm{~km}$ downwind of the farm. They presented two OWFs in the western 
324 United Kingdom and found that when the OWF was close to the shore, no significant reduction

325 in onshore precipitation was observed. In addition, they reported that a divergence zone was

326 associated with a downward motion, causing a reduction in precipitation downwind of the farms.

327 A sufficient distance between wind turbines in OWFs and the shore was needed for the

328 divergence zone to form, causing precipitation suppression near the shore.

The sensitivity results showed that not only the size and density of OWFs but also the distance of

331 farms from the shore should be considered because of the corresponding alterations in

332 meteorological conditions.

\section{Conclusions}

335 This study evaluated the potential effects of proposed OWFs on the atmospheric environment

336 when an extreme weather event, Tropical Storm Haitang as an example, occurred over Taiwan.

337 The WRF model (version 3.9) with a WFP scheme was employed in this study. According to the 338 energy policy of the Bureau of Energy, MOEA, the proposed OWFs with 711 wind turbines

339 (case 711-WTs), with a rated capacity of $5.688 \mathrm{GW}$, were implemented in the model.

341 Compared with observation, the control simulation without OWFs discovered an MSLP that was

342 slightly underestimated but generally exhibited the same trend. The WRF model could reproduce 343 the spatial distribution of accumulated precipitation, with the corresponding correlation

344 coefficient at 0.73 . Simulation results indicated that OWFs exerted significant effects on their 345 surroundings and even downwind over the western plain of Taiwan. As Tropical Storm Haitang 
made landfall in southern Taiwan and moved northward, its circulations would be blocked by the proposed OWFs. The presence of the OWFs was estimated to reduce the wind speed within the farms. Perturbations were generated upstream of the farms and then propagated downstream, which induced a significant downward motion, thus resulting in the formation of a divergence area. These processes affected wind speed, vertical velocity, moisture flux, radar reflectivity, precipitable water-vapor (PWV), precipitation as well as near-surface air temperature over western Taiwan, with the maximum alteration of $-2.6 \mathrm{~m} \mathrm{~s}^{-1},-5.5 \times 10^{-2} \mathrm{~m} \mathrm{~s}^{-1},-46 \mathrm{~g} \mathrm{~kg}^{-1} \mathrm{~m} \mathrm{~s}^{-1}$, $-35 \mathrm{dBZ},-3.1 \mathrm{~kg} \mathrm{~m}^{-2},-21 \mathrm{~mm} \mathrm{~h}^{-1}$ and $+0.4^{\circ} \mathrm{C}$, respectively. Sensitivity analysis was examined for the wind farm location and number and density of turbines, revealing their non-negligible influence.

\section{References}

1. IEA, 2020. Renewables 2020, IEA, Paris, https://www.iea.org/reports/renewables-2020

2. Baidya Roy, S., Pacala, S. \& Walko, R. Can large wind farms affect local meteorology? J. Geophys. Res. 109, D19101 (2004).

3. Christiansen, M. B. \& Hasager, C. B. Wake effects of large offshore wind farms identified from satellite SAR. Remote. Sens. Environ. 98, 251-268 (2005).

4. Keith, D. W. et al. The influence of large-scale wind power on global climate. Proc. Natl. Acad. Sci. 101, 16115-16120 (2004).

5. Vautard, R. et al. Regional climate model simulations indicate limited climatic impacts by operational and planned European wind farms. Nat. communications 5, 3196 (2014).

6. Wang, C. \& Prinn, R. G. Potential climatic impacts and reliability of very large-scale wind farms. Atmos. Chem. Phys. 10, 2053-2061 (2010). 
7. Siedersleben, S. K. et al. Micrometeorological impacts of offshore wind farms as seen in observations and simulations. Environ. Res. Lett. 13, 124012 (2018).

8. Pan, Y., Yan, C. \& Archer, C. L. Precipitation reduction during Hurricane Harvey with simulated offshore wind farms. Environ. Res. Lett. 13, 084007 (2018).

9. Al Fahel, N. \& Archer, C. L. Observed onshore precipitation changes after the installation of offshore wind farms. Bull. of Atmos. Sci.and Technol. 1, 179-203 (2020).

10. Tu, J.-Y. \& Chen, J.-M. Large-scale indices for assessing typhoon activity around Taiwan. Int. J. Climatol. 39, 921-933 (2019).

11. Skamarock, W. C. \& Klemp, J. B. A time-split nonhydrostatic atmospheric model for weather research and forecasting applications. J. Comput. Phys. 227, 3465-3485 (2008).

12. Hong, S.-Y., Dudhia, J. \& Chen, S.-H. A revised approach to ice microphysical processes for the bulk parameterization of clouds and precipitation. Mon. Wea. Rev. 132, 103-120 (2004).

13. Chen, F. \& Dudhia, J. Coupling an advanced land surface-hydrology model with the Penn State-NCAR MM5 modeling system. Part I: model implementation and sensitivity. Mon. Wea. Rev. 129, 569-585 (2001).

14. Nakanishi, M. \& Niino, H. An improved Mellor-Yamada level-3 model: Its numerical stability and application to a regional prediction of advection fog. Bound.-Layer Meteor. 119, 397-407 (2006).

15. Fitch, A. C. et al. Local and mesoscale impacts of wind farms as parameterized in a mesoscale NWP model. Mon. Wea. Rev. 140, 3017-3038 (2012).

16. Blahak, U., Goretzki, B. \& Meis, J. A simple parameterization of drag forces induced by large wind farms for numerical weather prediction models. Proc. European Wind Energy 
Conf. and Exhibition (EWEC), Warsaw, Poland, 186-189 (2010).

17. Proceedings of the European Wind Energy Conference and Exhibition 2010 (EWEC), Warsaw, Poland, 186-189 (2010).

18. Desmond, C. J., Murphy, J., Blonk, L. \& Haans, W. Description of an 8MW Reference Wind Turbine. J. Phys. Conf. Ser. 753, 092013 (2016).

19. Lin, C.-Y., Hsu, H.-m., Sheng, Y.-F., Kuo, C.-H. \& Liou, Y.-A. Mesoscale processes for super heavy rainfall of Typhoon Morakot (2009) over Southern Taiwan. Atmos. Chem. Phys. 11, 345-361 (2011).

20. Barthelmie, R. et al. Modelling and measuring flow and wind turbine wakes in large wind farms offshore. Wind Energy 12, 431-444 (2009).

21. Wu, Y.-T. \& Porté-Agel, F. Modeling turbine wakes and power losses within a wind farm using LES: an application to the Horns Rev offshore wind farm. Renew. Energ. 75, 945-955 (2015).

22. Porté-Agel, F., Bastankhah, M. \& Shamsoddin, S. Wind-turbine and wind-farm flows: a review. Bound.-Layer. Meteorol. 174, 1-59 (2020).

23. Lin, C.-Y. et al. The impact of channel effect on Asian dust transport dynamics: A case in southeastern Asia. Atmos. Chem. Phys. 12, 1-15 (2012).

\section{Acknowledgments}

The accomplishment of this work has financial support from the Project of Taiwan's Deep Decarbonization Pathways toward a Sustainable Society (Grant No. AS-KPQ-106-DDPP) from the Academia Sinica, Taiwan. The work is also partially supported by the Ministry of Science and Technology, Taiwan, under grants 108-2111-M-001-002 and 109-2111-M-001-004. 


\section{Author contributions}

417 C.Y. Lin conceived the idea, data interpretation, critical revision of the manuscript for important

418 intellectual content, and study supervision. Model simulation and data analysis contributed from

419 T.Y. Lee, Y.Y. Lin, Y.F. Sheng, and Y.T. Wu. T. Y. Lee and Y.Y. Lin drafted the manuscript. All

420 authors have contributed to the final manuscript.

421

\section{Competing interests}

423 The authors declare no competing interests.

424

\section{Additional information}

426 Supplementary information: separate file in PDF format.

427

428 
429 Table1. Summary of simulation cases and differences in accumulated precipitation compared 430 with that in CTRL over the west coastal area for the period 00:00 UTC to 23:00 UTC on July 30, $431 \quad 2017$.

\begin{tabular}{ccc}
\hline \hline Cases & No. of turbines & The average change of precipitation \\
& 0 & $\mathrm{~mm}(\%)$ \\
\hline CTRL & 711 & $-7.6(-6.1 \%)$ \\
\hline 711-WTs & 178 & $-6.9(-5.9 \%)$ \\
\hline 178-WTs & 711 & $-1.8(-2.1 \%)$ \\
\hline 711-WTs_W & 711 & $-8.7(-7.3 \%)$ \\
\hline 711-WTs_E & 710 \\
\hline
\end{tabular}

432

433

434

435 
(a)

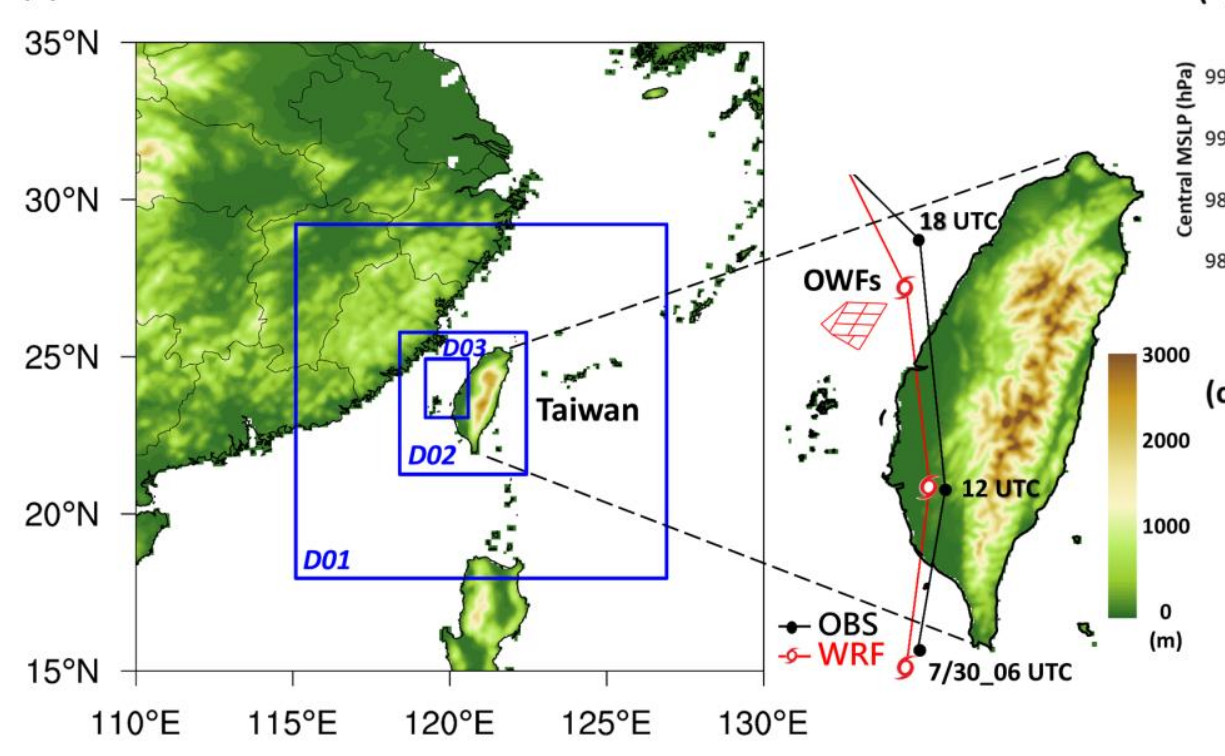

(b)

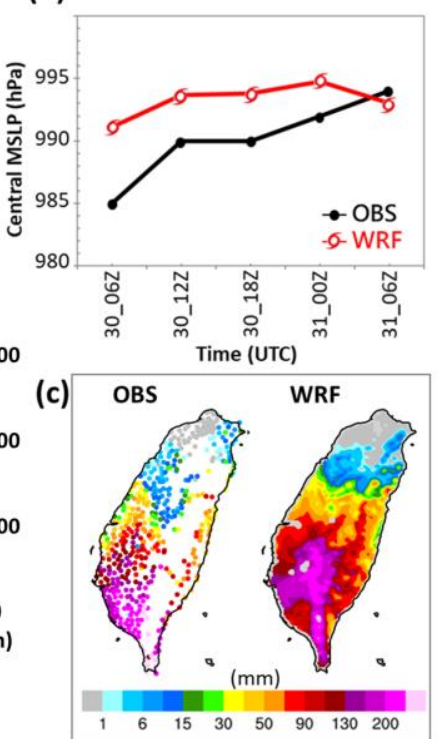

437 Figure 1. (a) Configuration of Weather Research and Forecasting model domain, topography,

438 location of proposed offshore wind farms (OWFs) over Taiwan, and the comparisons of

439 observed data and WRF model CTRL simulation of the track. OWFs location were indicated by

440 the red area nearby western Taiwan. D01, D02 and D03 indicate simulation domain 1, domain

4412 and domain 3, respectively. (b) Comparisons of observed (black line) and WRF model CTRL

442 simulation (red line) in central minimum sea level pressure, and (c) Observed and simulated

443 accumulation precipitation over Taiwan during the period 06:00 UTC to 18:00 UTC 30 July 2017. 
7/29 00 UTC

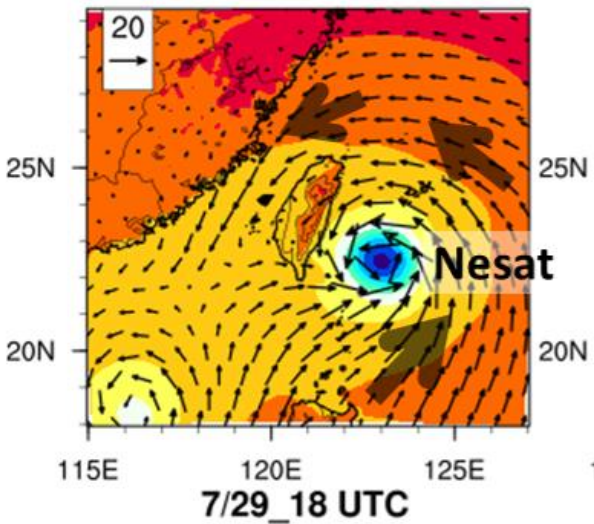

7/29 06 UTC

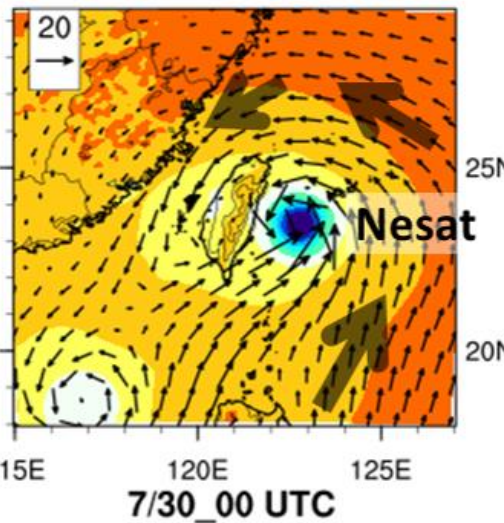

7/29 12 UTC

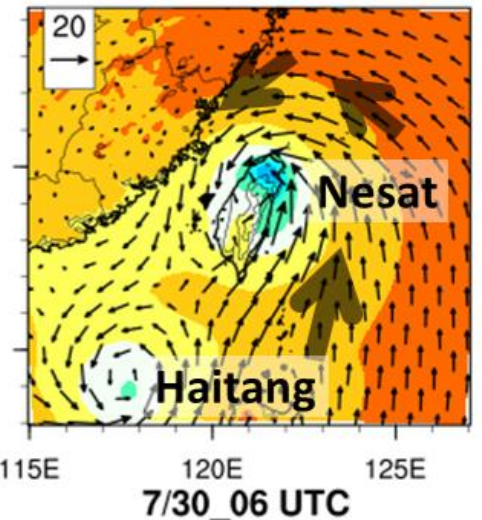

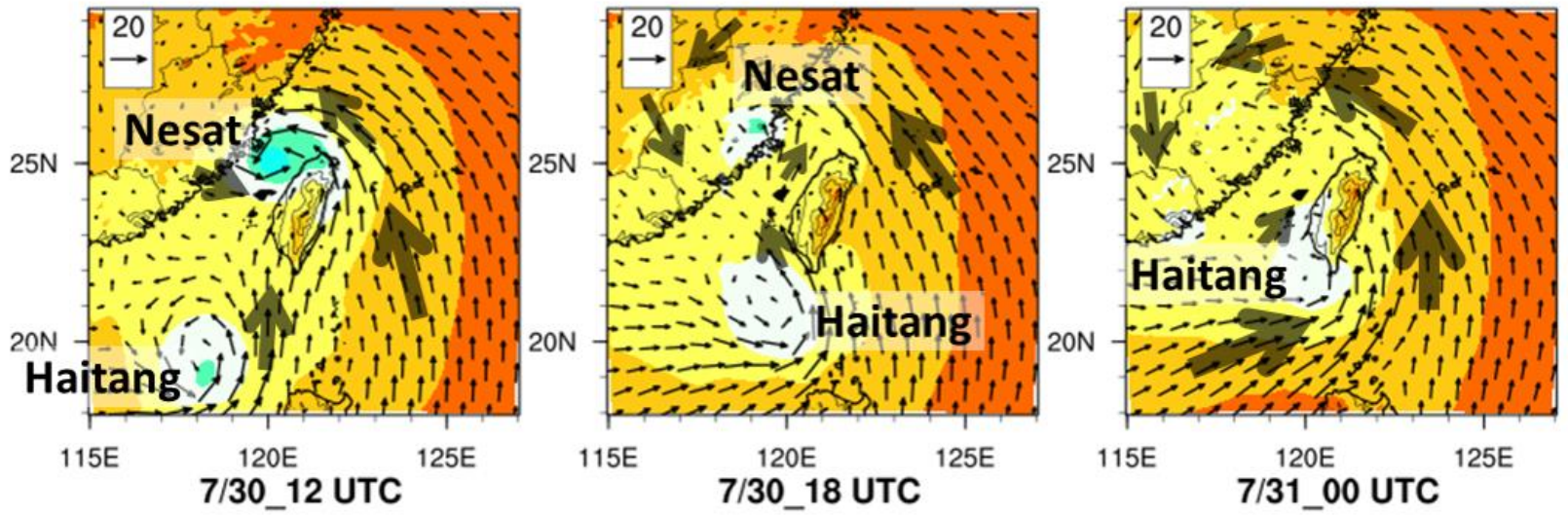

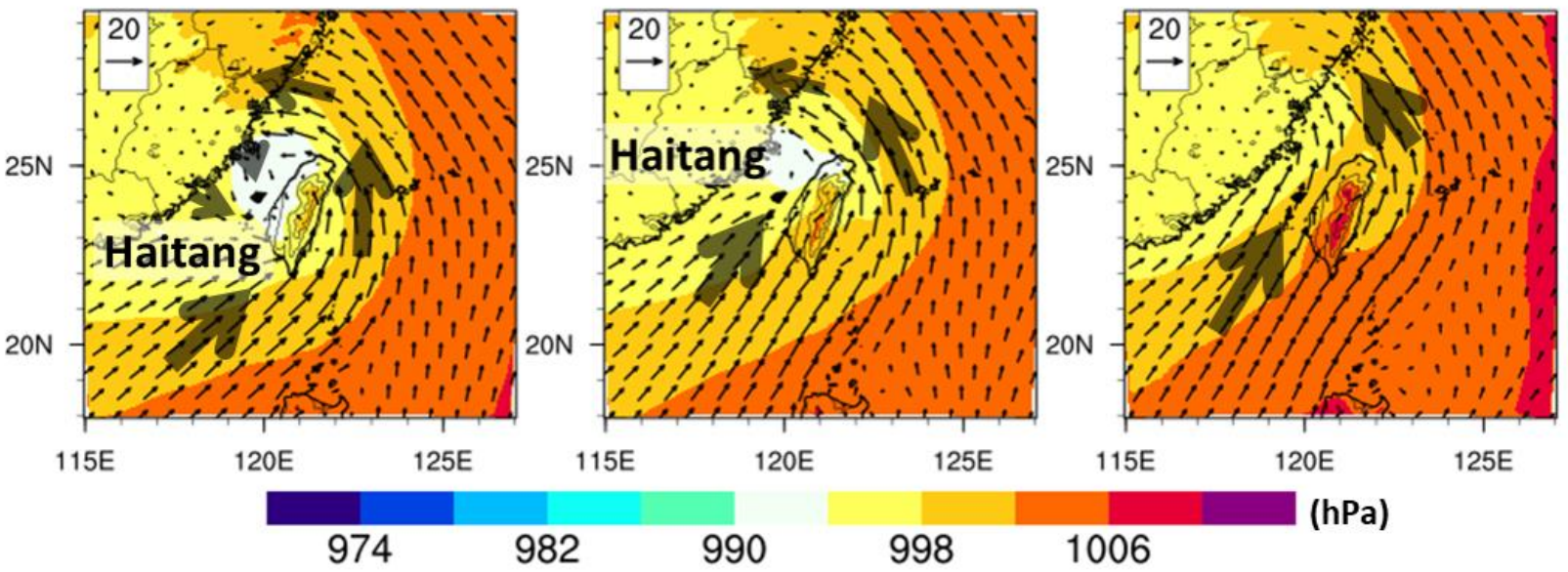

447 July, 2017. 

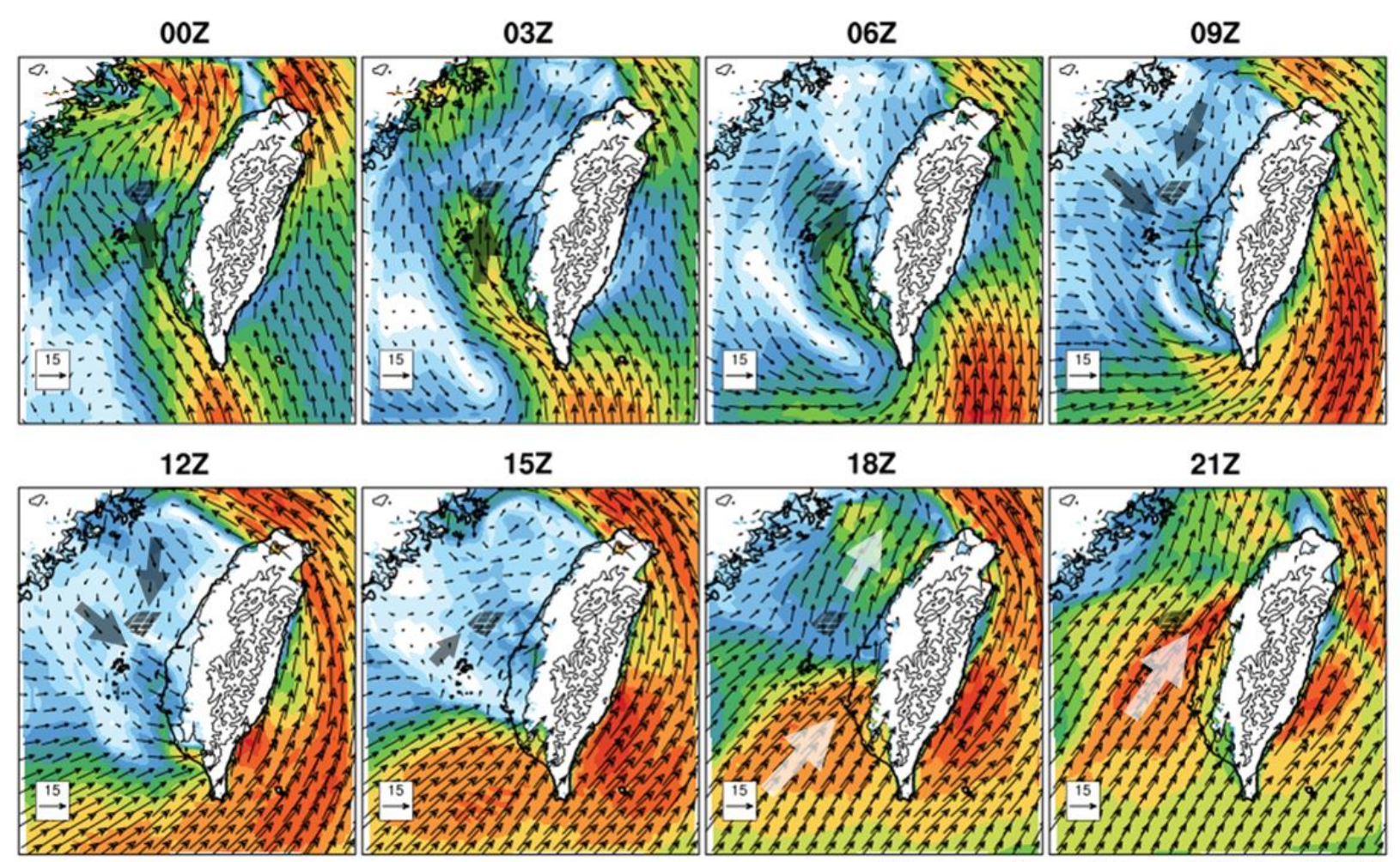

212
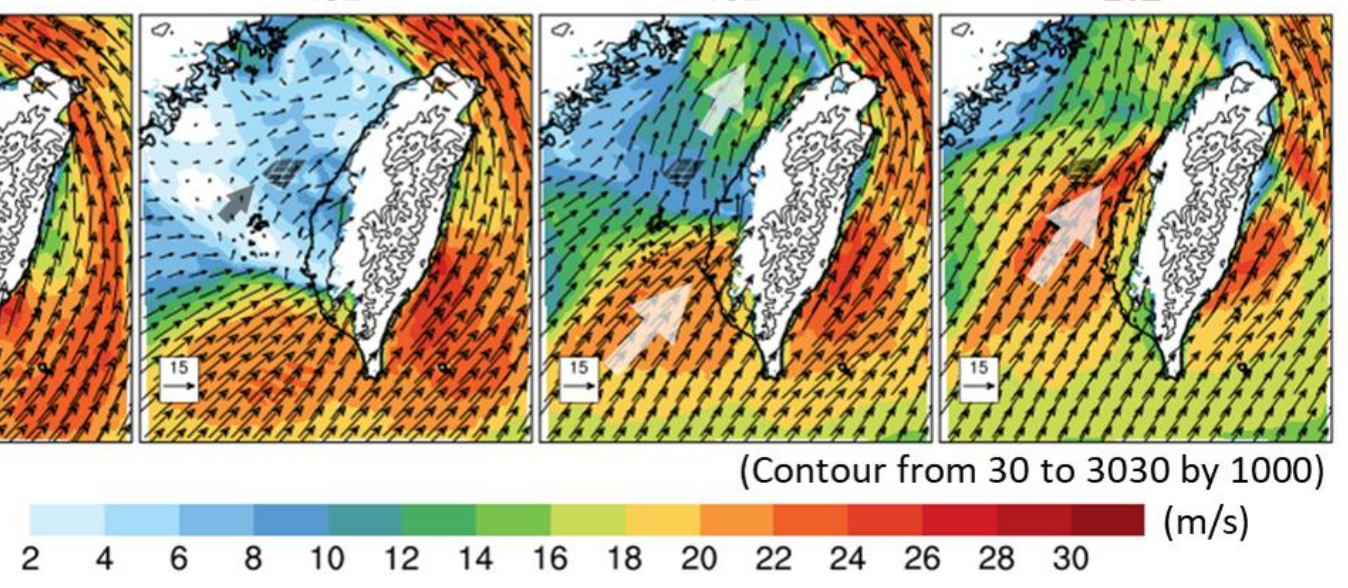

(Contour from 30 to 3030 by 1000)

450

451

452 453

Figure 3. Hub-height $(110 \mathrm{~m})$ horizontal wind speed (shaded, $\mathrm{m} \mathrm{s}^{-1}$ ) and horizontal wind (vector, $\mathrm{m} \mathrm{s}^{-1}$ ) during 00:00-21:00 UTC on July 30, 2017. The black contour lines indicate the elevation of Taiwan (m). The contour interval is $1000 \mathrm{~m}$ from $30 \mathrm{~m}$ to $3030 \mathrm{~m}$. 

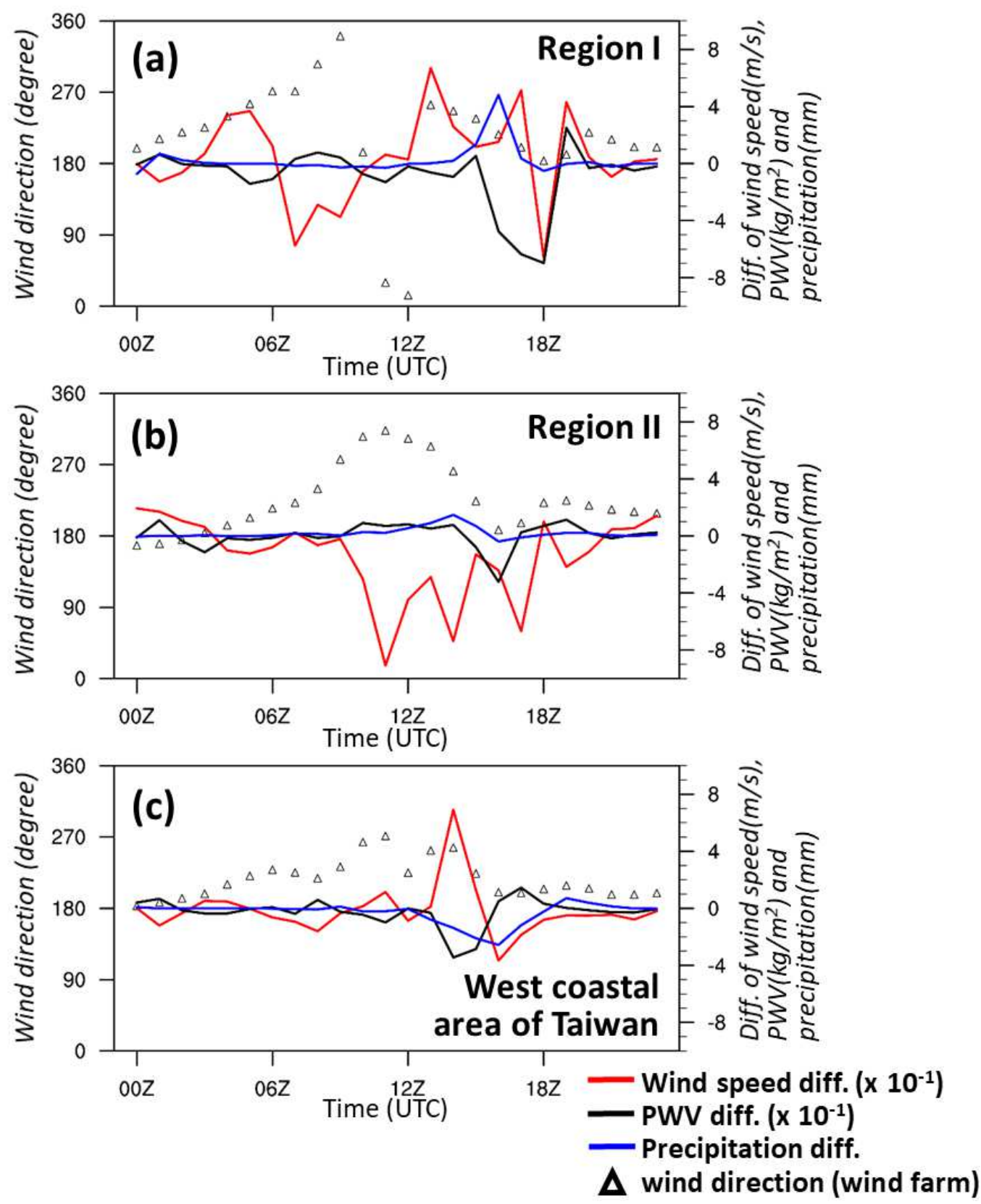

455 Figure 4. Area-mean of the time series of differences in hub-height wind speed (red lines, right 456 axis, $\times 10^{-1}, \mathrm{~m} \mathrm{~s}^{-1}$ ), precipitable water-vapor (PWV, black lines, right axis, $\times 10^{-1}, \mathrm{~kg} \mathrm{~m}^{-2}$ ) and 457 precipitation (blue lines, right axis, $\mathrm{mm}$ ) between 711-WTs and CTRL simulations, and the area458 mean wind direction (denoted by the black triangle symbol, left axis, degree) of 711-WTs 459 simulation during 00:00-23:00 UTC on July 30, 2017. (a) region I, (b) region II and (c) the west 460 coastal area of Taiwan. Those areas were indicated by the red box, blue box and the grey 461 slashed area, respectively in Fig. 5a. 

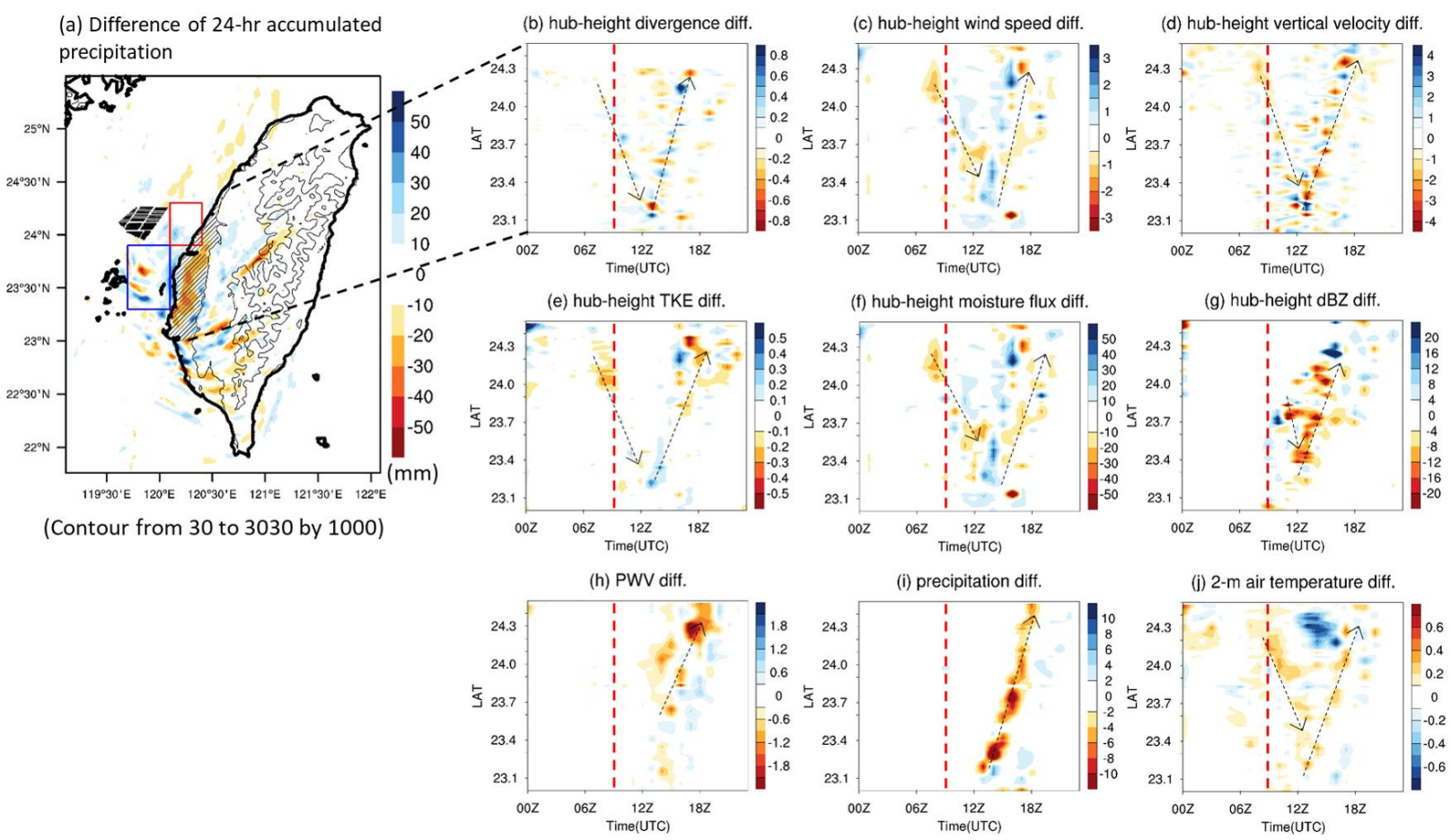

Figure 5. (a) Difference in 24-hour accumulated precipitation ( $\mathrm{mm}$ ) between 711-WTs and CTRL

464 simulations over Taiwan during 00:00-23:00 UTC on July 30, 2017. The gray diagonally lined area represents the west coastal area of Taiwan. Time-latitude diagrams of differences between 711-WTs and CTRL simulations at hub-height (b) divergence $\left(\times 10^{-3}, \mathrm{~s}^{-1}\right)$, (c) wind speed $\left(\mathrm{m} \mathrm{s}^{-1}\right)$, (d) vertical velocity $\left(\times 10^{-2}, \mathrm{~m} \mathrm{~s}^{-1}\right),(\mathrm{e})$ TKE $\left(\mathrm{m}^{2} \mathrm{~s}^{-2}\right),(\mathrm{f})$ moisture flux $\left(\mathrm{g} \mathrm{kg}^{-1} \cdot \mathrm{m} \mathrm{s}^{-1}\right)$, (g) reflectivity (dBZ), (h) precipitable water-vapor (PWV, $\mathrm{kg} \mathrm{m}^{-2}$ ), (i) precipitation $(\mathrm{mm})$ and (j) 2$\mathrm{m}$ air temperature $\left({ }^{\circ} \mathrm{C}\right)$. Averaging from $\mathrm{E}-\mathrm{W}$ direction over the west coastal area of Taiwan

470 (indicated by the grey slashed area in Fig. 5a. The red dashed lines indicate the time when 471 Tropical Storm Haitang made landfall at 09 UTC. The black contour lines in Fig. 5a indicate the 472 elevation of Taiwan (m). The contour interval is $1000 \mathrm{~m}$ from $30 \mathrm{~m}$ to $3030 \mathrm{~m}$. The black dashed 473 arrows in Fig. $5 b-j$ represent the direction of propagation. 
(a) Horizontal wind speed at hub-height

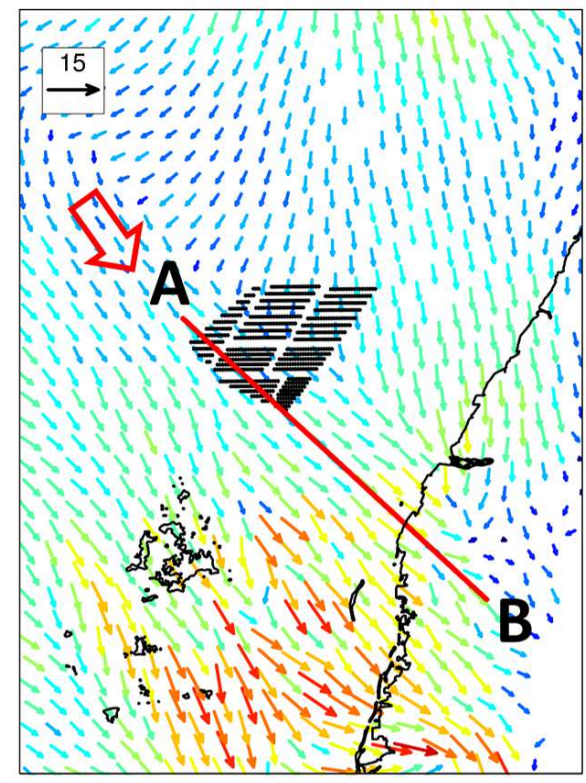

$\begin{array}{lllllllllll}1 & 2 & 3 & 4 & 5 & 6 & 7 & 8 & 9 & 101112\end{array}$

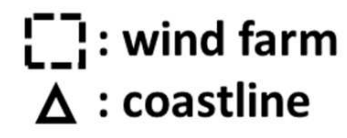

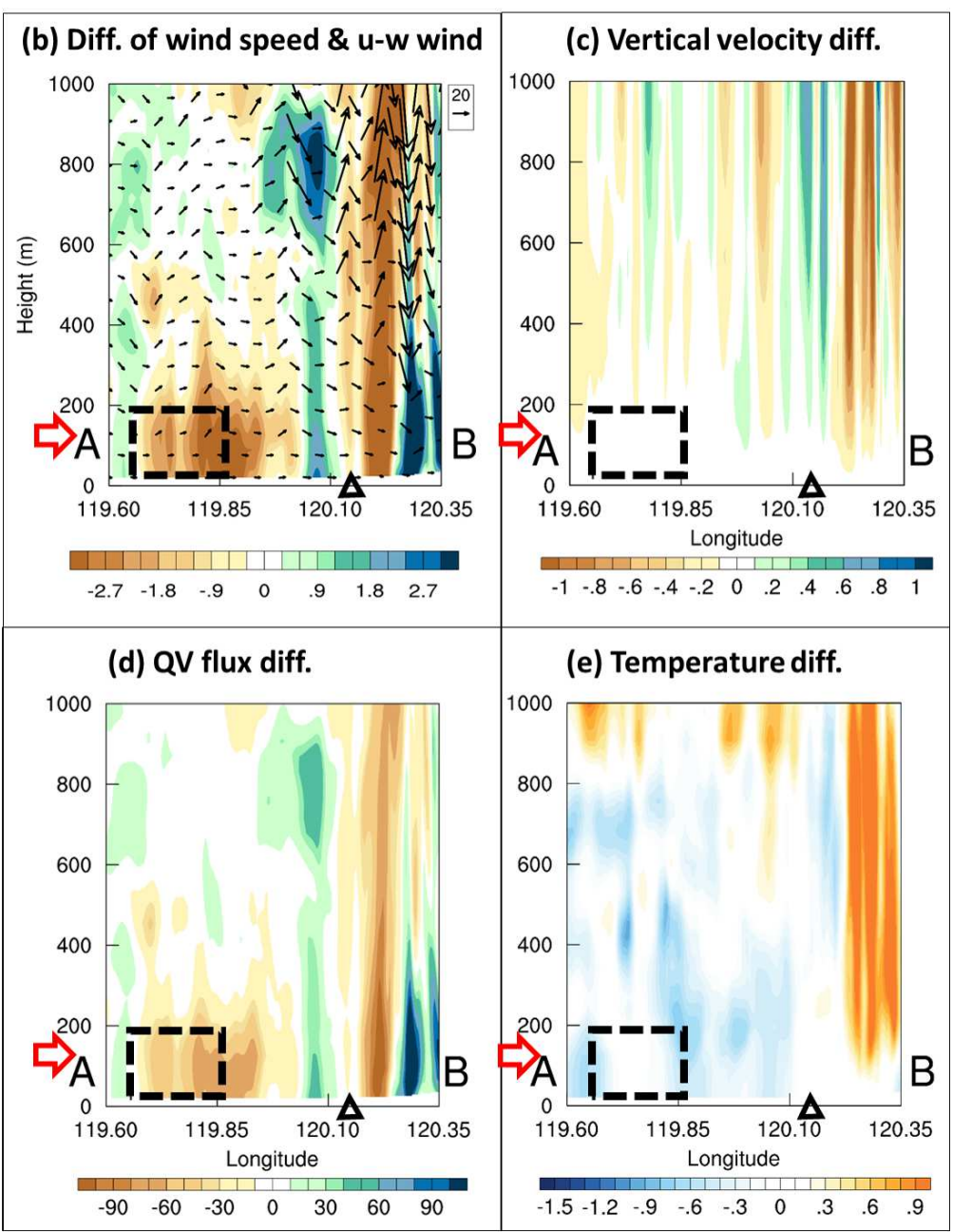

Figure 6. Vertical cross-sectional diagram of simulation differences between case 711-WTs and CTRL along the line AB at 11:00 UTC on July 30, 2017: (a) horizontal hub-height wind speed in case 711-WTs (vector, $\mathrm{m} \mathrm{s}^{-1}$ ), (b) horizontal wind speed difference (shaded, $\mathrm{m} \mathrm{s}^{-1}$ ) and $\mathrm{u}$-w wind vectors in case 711-WTs ( $\mathrm{w}$-wind: $\left.\times 10^{-2}, \mathrm{~m} \mathrm{~s}^{-1}\right),(\mathrm{c})$ vertical velocity difference $\left(\mathrm{m} \mathrm{s}^{-1}\right),(\mathrm{d})$ moisture flux difference $\left(\mathrm{g} \mathrm{kg}^{-1} \cdot \mathrm{m} \mathrm{s}^{-1}\right)$, and $(\mathrm{e})$ temperature difference $\left({ }^{\circ} \mathrm{C}\right)$. The black triangle represents the coastline, and the location of offshore wind farms is marked with a dashed-line square. 
(a) $178-W T s, A V G=-6.9 \mathrm{~mm}(-5.9 \%)$

(b) 711-WTs_W, AVG $=-1.8 \mathrm{~mm}(-2.1 \%)$ (c) $711-W T s \_E, A V G=-8.7 \mathrm{~mm}(-7.3 \%)$
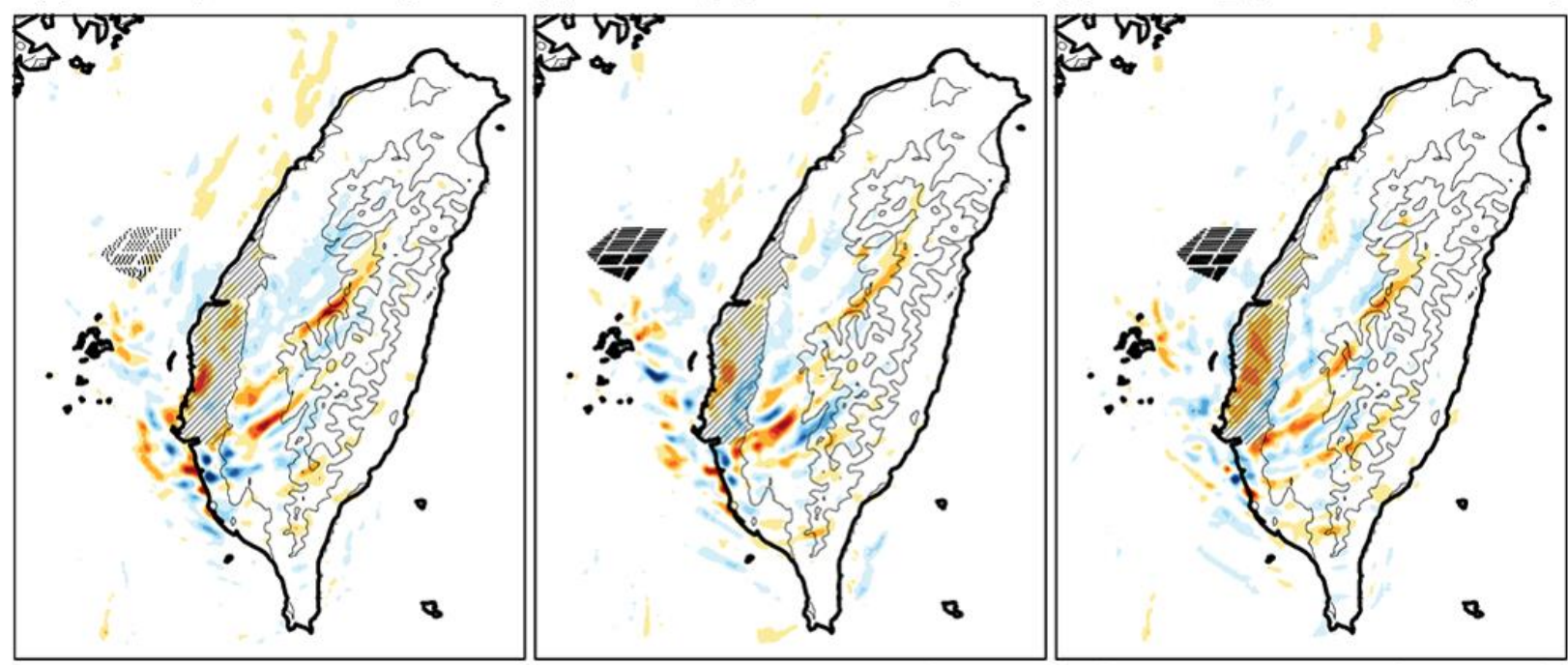

(Contour from 30 to 3030 by 1000)

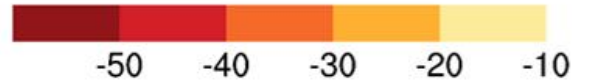

$0 \quad 10$

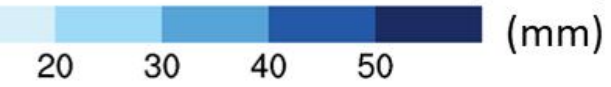

Figure 7. Same as Fig. 5a except for the differences between the sensitivity cases and CTRL over

Taiwan during 00:00-23:00 UTC on July 30, 2017 (a) case 178-WTs, (b) case 711-WTs_W, and (c)

487 case 711-WTs_E. 
(a) 711-WTs

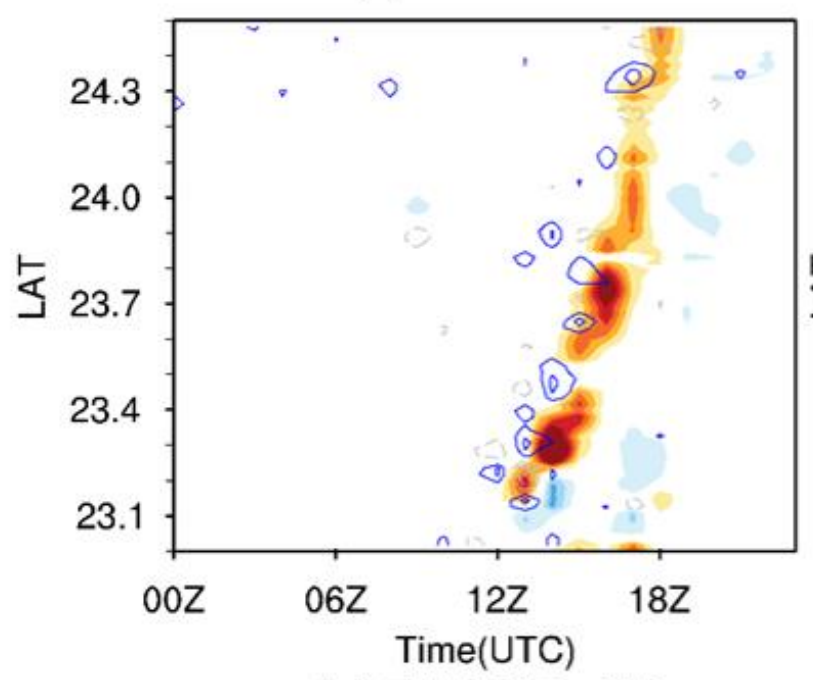

(c) 711-WTs_W

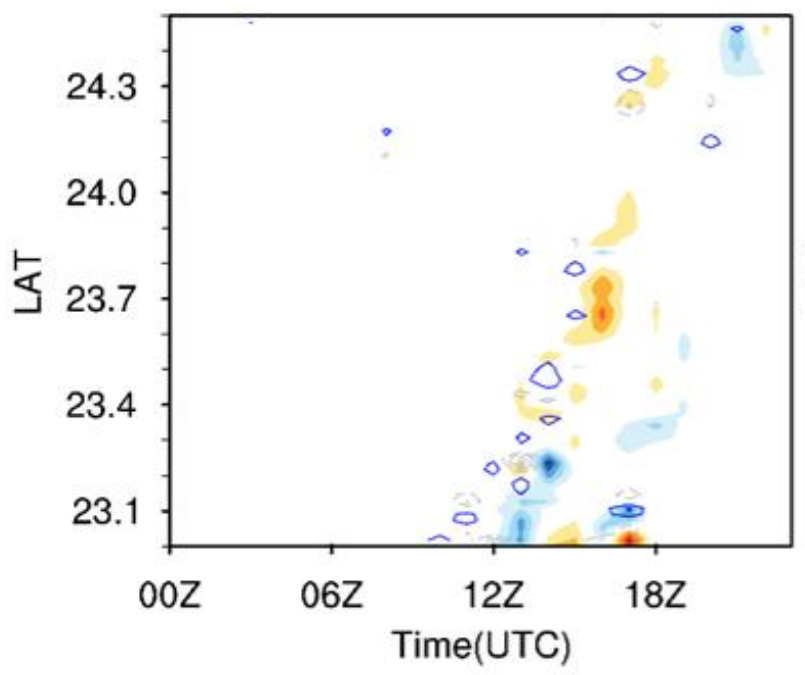

(b) 178-WTs

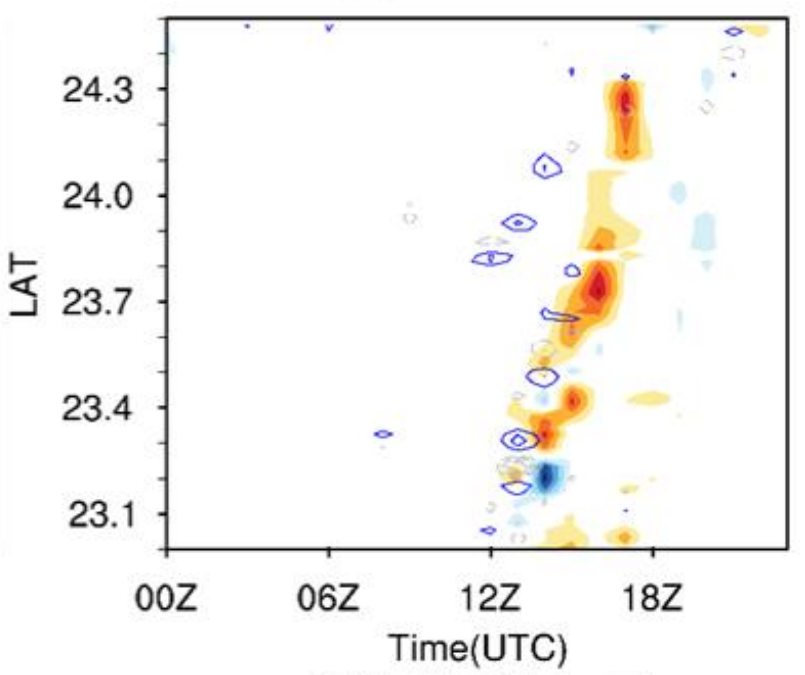

(d) 711-WTs_E

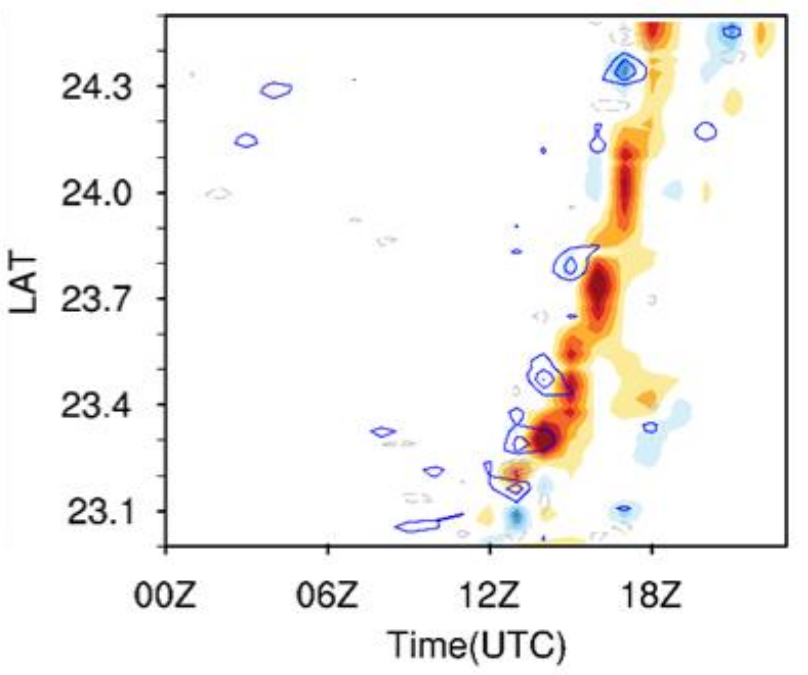

489

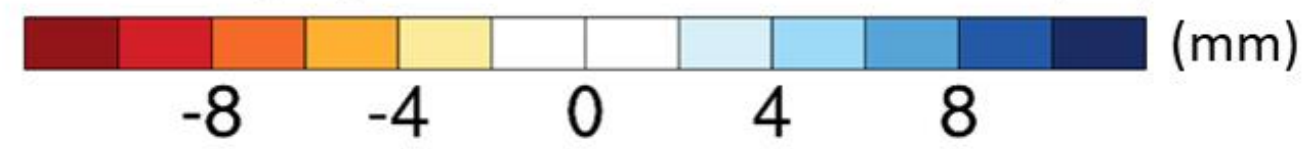

490 Figure 8. Same as Fig. 5b-j except for the differences between the sensitivity cases and CTRL in

491 precipitation (colored, $\mathrm{mm}$ ) and 10-m divergence (contour interval was $1.5 \times 10^{-4}$, from $-6 \times$

$49210^{-4}$ to $6 \times 10^{-4}, \mathrm{~s}^{-1}$ ): (a) case 711-WTs, (b) case 178-WTs, (c) case 711-WTs_W, and (d) case 711493 WTs_E. 


\section{Supplementary Files}

This is a list of supplementary files associated with this preprint. Click to download.

- SciRepsupplementaryfinal.pdf 